\title{
pombalina
}

(8)

\section{O poema "Thetis Sacra": uma incursão de D. Francisco Manuel de Melo no género} épico
Autor(es):
Fardilha, Luis
Publicado por: Imprensa da Universidade de Coimbra; Ediciones Universidad
URL
persistente:
URI:http://hdl.handle.net/10316.2/31526
DOI:
DOI:http://dx.doi.org/10.14195/978-989-26-0245-5_15
Accessed : $\quad$ 26-Apr-2023 13:19:00

A navegação consulta e descarregamento dos títulos inseridos nas Bibliotecas Digitais UC Digitalis, UC Pombalina e UC Impactum, pressupõem a aceitação plena e sem reservas dos Termos e Condições de Uso destas Bibliotecas Digitais, disponíveis em https://digitalis.uc.pt/pt-pt/termos.

Conforme exposto nos referidos Termos e Condições de Uso, o descarregamento de títulos de acesso restrito requer uma licença válida de autorização devendo o utilizador aceder ao(s) documento(s) a partir de um endereço de IP da instituição detentora da supramencionada licença.

Ao utilizador é apenas permitido o descarregamento para uso pessoal, pelo que o emprego do(s) título(s) descarregado(s) para outro fim, designadamente comercial, carece de autorização do respetivo autor ou editor da obra.

Na medida em que todas as obras da UC Digitalis se encontram protegidas pelo Código do Direito de Autor e Direitos Conexos e demais legislação aplicável, toda a cópia, parcial ou total, deste documento, nos casos em que é legalmente admitida, deverá conter ou fazer-se acompanhar por este aviso.

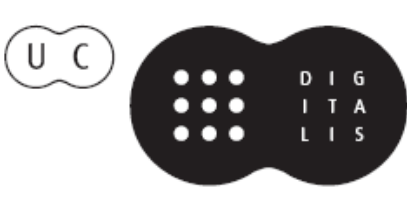


Marta Teixeira Anacleto

Sara Augusto

Zulmira Santos

Coordenação

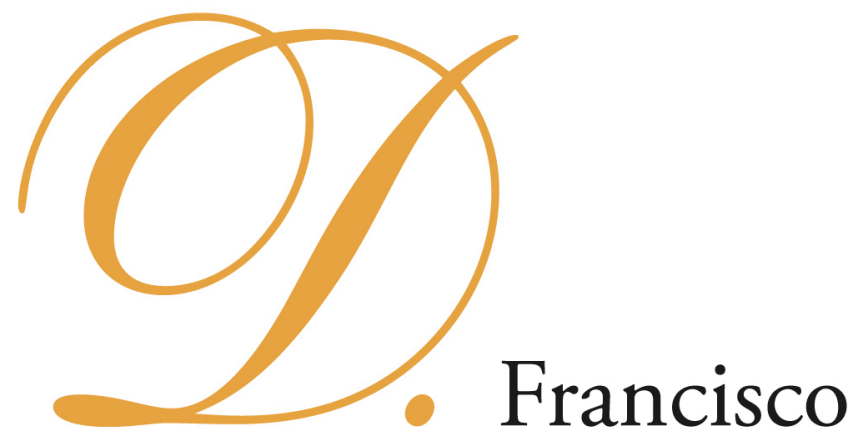

Manuel de Melo e o

Barroco Peninsular 


\title{
EDIĈ̣̃O
}

Imprensa da Universidade de Coimbra Ediciones Universidad Salamanca

\section{COORDENAÇÃo EDITORIAL}

Imprensa da Universidade de Coimbra

URL: http://www.uc.pt/imprensa_uc

Vendas online: http://www.livrariadaimprensa.com

\section{CONCEPÇÃO GRÁFICA}

António Barros

\section{REVISÃO TEXTO}

Sara Augusto

\author{
Pré-Impressão, Impressão e ACABamento \\ www.artipol.net
}

\section{IS B N}

978-989-26-0044-4 (Portugal)

978-84-7800-194-1 (Espanha)

DEPósito LEGAL

$311680 / 10$

OBRA PUBlicada COM O APOIO DE:

FCT Fundação para a Ciência e a Tecnologia

MINISTÉRIO DA CIÊNCIA, TECNOLOCIA E ENSINO SUPERIOR Portugal

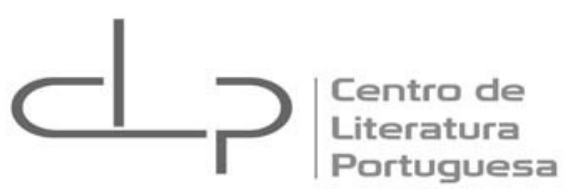

A presente publicação insere-se no Grupo "Poéticas" (coordenação de Marta Teixeira Anacleto) do Centro de Literatura Portuguesa, Unidade de I\&D financiada pela Fundação para a Ciência e a Tecnologia, ao abrigo do Programa Operacional Ciência e Inovação 2010.

(C) Agosto 2010

IMPRENSA DA UNIVERSIDADE DE COIMBRA

EDICIONES UNIVERSIDAD DE SALAMANCA 
Marta Teixeira Anacleto

Sara Augusto

Zulmira Santos

Coordenação

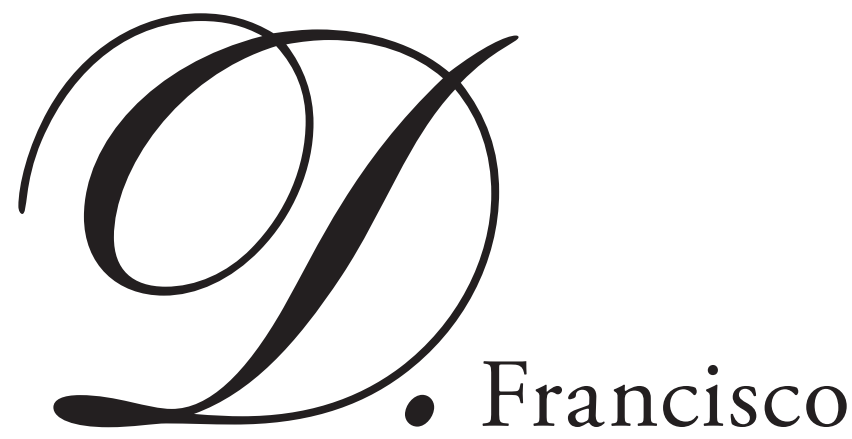

Manuel de Melo e o Barroco Peninsular

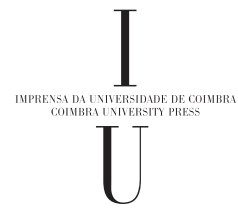


PARTE III

MODALIDADES DE ESCRITA DO BARROCO EM D. Francisco Manuel de Melo 


\author{
Luis Fardilha \\ Universidade do Porto
}

\title{
O PEOMA «THETIS SACRA»: \\ UMA INCURSĀO DE D. FRANCISCO MANUEL DE MELO NO GÉNERO ÉPICO
}

Como se sabe, D. Francisco Manuel de Melo meditou longamente a ediçáo das suas obras $^{1}$. A publicação tardia dos muitos trabalhos que produziu, apesar de não ter sido desejada, permitiu-lhe pensar e propor um mapa de conjunto, destinado a orientar o modo como deveriam sair dos prelos para as mãos dos seus leitores ${ }^{2}$. Os dois volumes das Obras Morales e o volume das Obras Métricas representam o início da execução desse projecto, o qual, por razóes de todos sabidas, não pôde ir além destas escassas primícias. Ainda assim, temos de reconhecer que a organização destes primeiros volumes, tendo sido meditada ao longo duma vida, não pode deixar de obedecer a critérios bem definidos, pelo que o modelo organizativo a que obedecem terá seguramente um sentido e um significado susceptível de decifração. Pela sua amplitude, complexidade e organicidade, merece particular atenção o volume das Obras Métricas.

A base em que assenta o princípio orientador de todo o conjunto, a divisão por Musas, remonta a 1649 e à edição de Las tres Musas del Melodino. A ideia inspiradora, tê-la-á o autor encontrado em Marcello Macedonio ${ }^{3}$, de acordo com uma passagem do apólogo «Hospital das Letras»:

\footnotetext{
${ }^{1}$ Sabemos que D. Francisco Manuel de Melo ponderava, pelo menos desde 1647 - dois anos antes da edição princeps de Las Três Musas del Melodino (Lisboa: Oficina Craesbeeckiniana, 1649) -, publicar «alguma obra» no estrangeiro (cf. carta a um amigo, de 24 de Julho de 1647, em Cartas Familiares, prefácio e notas de Maria da Conceição Morais Sarmento. Lisboa: 1981, p. 155) e que mantinha esta intenção em 1649 (cf. carta a um amigo ausente, de 7 de Maio, em Cartas Familiares, ed. cit., p. 249). Por outro lado, o plano de edição que gizou para o conjunto das suas obras e que incluiu nos paratextos da «Primera Parte» da ediçáo romana das Obras Morales (1664) é bem ilustrativo da sua preocupação com o modo como desejava que os seus trabalhos literários chegassem ao público.

${ }^{2} \mathrm{O}$ plano de edição que gizou para o conjunto das suas obras foi incluído nos paratextos da «Primera Parte» da edição romana das Obras Morales (1664).

3 Marcello Macedonio, Le nove Muse di Marcello Macedonio raccolte e date alla stampa da Pietro Macedonio suo fratello all'ill.mo e rev.mo sig.re il sig.r cardinale Borghese. Nápoles: Tarquinio Longo, 1614.
} 
Bocalino. Assim seja, e acabe também o Senhor Dom Francisco de Quevedo com as suas Musas, e faça nove, sem temor de que se diga, por este nove fora nada; antes ficando sòmente seis, pode dizer algum velhaco, vendo tal meia dúzia, que nem é inda poeta das dúzias senão das meias dúzias que é menos ametade.

Quevedo. O invento não foi meu, mas do Macedónio, poeta italianno, que nesta maneira publicou suas obras.

Autor. Certo que não sabia eu que o Quevedo tinha tal pensamento, quando constituí em título de As três Musas, essas poucas obras, que andam impressas com o meu nome. ${ }^{4}$

De acordo com esta arquitectura global, podemos encontrar nas Obras Métricas de 1665 três coros de três Musas cada, sendo o primeiro conjunto a reproduçáo praticamente exacta da obra que saíra da oficina Craesbeeckiana dezasseis anos antes ${ }^{5}$, a que se acrescentou El Panteón na ediçáo lionesa. A segunda parte apresenta como característica unificadora mais evidente a utilização da língua portuguesa. Apesar de ter permanecido inédita até 1665, D. Francisco pensara publicar no estrangeiro a sua obra poética em português muitos anos antes, quando estavam para aparecer à luz as primeiras três Musas castelhanas. De facto, numa carta datada de 7 de Maio de 1649 e dirigida «a um amigo ausente», podemos ler:

Eu tenho aqui um volume de versos portugueses, e tanto, que parecem escritos há duzentos anos. Desejo estampá-los limpamente e com o meu nome, à diferença dos castelhanos, que creo sairão à luz brevemente com algum suposto. Muito quisera que a impressão se fizesse nessa terra, mas à falta de correcção me detenho. Se a assistência de V. M. desse lugar à emenda e a alcançar o fim da obra, não me seria dificultoso mandar lá o original, bem castigado, para que V. M. dispusesse sua estampa; e com ele faria ir os efeitos do seu dispêndio. ${ }^{6}$

Como esta vontade do autor náo teve efeito, as Musas portuguesas saídas dos prelos de Lyon abarcam a totalidade da produção poética em português do autor, sem limitaçôes cronológicas. Mesmo os textos mais recentes aí são incluídos, nomeadamente os que resultaram da participação de D. Francisco nas actividades da Academia dos Generosos, como exaustivamente aponta Antonio Bernat Vistarini? .

«El Tercer Coro de Las Musas del Melodino», última parte das Obras Métricas, recolhe sobretudo produçóes em castelhano posteriores à organização do volume editado em 1649, ou que aí não tinham aparecido.

\footnotetext{
${ }^{4}$ Jean Colomès, Le dialogue 'Hospital das Letras' de D. Francisco Manuel de Melo, texte établi d'après l'édition princeps et les manuscrits, variantes et notes. Paris: 1970, pp. 66-67.

${ }^{5}$ As diferenças são mínimas: a dedicatória, que era assinada em 1649 por Henrique Valente de Oliveira - o editor que tinha custeado a impressão - e datada de 5.10.1649, é agora subscrita simplesmente por "El impresor» e não está datada; a outra diferença consiste na supressão de um texto dirigido "Al lector».

${ }^{6}$ D. Francisco Manuel de Melo, Cartas Familiares, ed. cit., p. 249.

${ }^{7}$ Antonio Bernat Vistarini, Francisco Manuel de Melo (1608\$1666). Textos y contextos del Barroco peninsular. Palma: 1992, pp. 169-170.
} 
Se atentarmos em cada uma das três partes em que se organiza a edição de Lyon, poderemos verificar que cada conjunto repete, com alguma necessária adaptação, o mesmo modelo organizativo. A primeira Musa de cada conjunto ("El Harpa de Melpomene», "A Tuba de Calíope» e "La Lira de Clío») recolhe exclusivamente sonetos (mesmo se na sétima aparece uma estranha designação de «Epigramas»...); as segundas Musas («La Cítara de Erato», "A Sanfonha de Euterpe» e "La Avena de Tersícore») apresentam igualmente uma clara unidade genológica, sendo a Cítara preenchida com romances, a Sanfonha com éclogas e cartas, enquanto a Avena reúne tonos e romances, o que, segundo explica Vistarini ${ }^{8}$, acaba por constituir um mesmo género lírico, uma vez que os tonos não são mais do que romances musicados. Por fim, as terceiras Musas de cada conjunto abrigam uma grande variedade de formas poéticas que contrastam, pela diversidade, com a homogeneidade das restantes secçóes. O modelo organizativo a que obedece a edição de 1665 das Obras Métricas prolonga, pois, multiplicando-a, aquela que tinha sido ensaiada em 1649 com Las Tres Musas del Melodino.

Se descontarmos os textos em prosa, verificaremos que cada uma das terceiras Musas dos três coros encerra com uma composição longa, estruturalmente autónoma e que teve, ou poderia ter, uma vida editorial própria. Assim, o primeiro coro fecha com o Panteón, que tinha sido editado em 1650, em Lisboa, enquanto o coro das Musas portuguesas termina com o Auto do fidalgo aprendiz, o qual haveria de ter, depois desta primeira edição nas Obras Métricas, uma fortuna editorial autónoma, tendo sido objecto duma publicaçáo isolada uma década depois, em 1676, em Lisboa'. Tendo em conta o princípio de regularidade a que obedece a arquitectura global destas Obras Métricas, ganha um relevo particular, pela posição que nelas ocupa, o poema "Thetis Sacra», que encerra o último coro de Musas castelhanas. Tal como foi publicado, este texto náo parece corresponder, nem pela extensão, nem pelo significado, às outras composiçóes que ocupam o último lugar na distribuição proposta por D. Francisco Manuel de Melo. Sabido, no entanto, que neste último terço das Obras Métricas foram reunidos alguns dos trabalhos mais recentes do autor, é legítimo perguntarmo-nos se a posição de fecho estaria reservada para este poema, porque ele deveria ser mais extenso e mais elaborado, tendo sido incluído à última hora, numa versão ainda provisória e longe da perfeição inicialmente pensada e que justificaria o destaque de figurar em posição de fecho, não apenas de um dos coros, mas de todo o conjunto ${ }^{10}$. Se equacionarmos a hipótese de que este deveria ser o poema épico que

${ }^{8}$ Antonio Bernat Vistarini, Francisco Manuel de Melo (1608\$1666). Textos y contextos del Barroco peninsular, ed. cit., p. 171, n. 409.

${ }^{9}$ Para uma informação completa sobre a tradição impressa do Auto do Fidalgo Aprendiz, deverá consultar-se a recente edição crítica desta obra preparada por Evelina Verdelho (D. Francisco Manuel de Melo, O Fidalgo Aprendiz, introdução, notas e índice de formas de Evelina Verdelho. A Coruña: 2007), em especial as páginas pp. 72-91.

${ }^{10} \mathrm{O}$ autor manifesta ter consciência das imperfeiçóes que a edição de Lyon apresenta, assumindo-as, no texto dirigido «A los lectores de mis Obras Métricas», onde comete ao leitor - numa fórmula que pretenderá, com agudeza, conferir uma dimensão positiva a esses «defeitos» - a responsabilidade de "completar» a sua obra: «Pero, de todas suertes, ya me prometo, oh letor mío cortesísimo, que si en esta escritura hallases algunos destos breves defetos, te des por obligado a detenerte a emendarlos, porque el autor no solo te pide que corrijas las letras, mas que realces 
não encontramos em toda a vasta produção reunida no volume, poderemos propor uma boa razão para esta posição de destaque.

A realização dum poema épico deveria corresponder, para os poetas que se submetiam ao princípio da imitaçáo dos antigos, ao culminar da carreira literária, de acordo com uma progressão semelhante à de Virgílio, o qual chegara à epopeia depois de se ter iniciado na humilde poesia bucólica e de ter aperfeiçoado a técnica e aprofundado o saber na elaboração das Geórgicas. Não surpreenderia, assim, que um polígrafo da dimensão de D. Francisco Manuel de Melo, que via na carreira das Letras uma alternativa à interrompida carreira das Armas $^{11}$ por que inicialmente se tinha decidido, desejasse encerrar as suas Obras Métricas com um poema épico. Poderia a "Thetis Sacra» ser essa obra?

Tanto a «alegoria do poema», revelada no final da composição, como os elementos mais salientes da sua estrutura externa permitem, pelo menos, pôr a hipótese. $\mathrm{Na}$ sinopse aposta às 102 oitavas publicadas em 1665 pode ler-se:

La idea deste Poema Misto es cantar com todos los adornos de la poesía cristiana la piedosísima acción que obraron los portugueses en el descubrimiento del Oriente, haciendo, por manos de sus sacerdotes, celebrar la primera misa que jamás en el mundo se había celebrado sobre el mar, cuyo ejemplo seguieron después las naciones católicas. Discúrrese por los monarcas cristianos que dilataron la fe y se engrandecen los reyes y príncipes de Portugal que más se emplearon en las conquistas de los infieles, haciendo venerar por nuevas regiones el nombre de Cristo, guardar su santa ley y conocer su santísima cruz. ${ }^{12}$

O primeiro apontamento que a explicação de D. Francisco Manuel de Melo suscita será a classificação da "Thetis Sacra» como "poema misto». Esta designaçáo, longe de nos afastar do âmbito da poesia considerada épica, coloca a obra em relação com um grupo de composiçôes que geralmente são incluídos neste domínio. Com efeito, se procurarmos precisar o significado da expressão "poema misto», poderemos encontrar alguma resposta no discurso crítico produzido pelo próprio autor. Percorrendo o apólogo Hospital das Letras, encontraremos a referida designação atribuída a duas obras. A primeira surge-nos a propósito do poema Araucana do poeta espanhol Alonso de Ercilla y Zúniga. Referindo-se ao autor,

las palabras y retoques las sentencias, pues desta suerte quedará más veces tuyo este mi libro, no ya tanto porque le hás comprado y porque le hás entendido, mas porque le habrás perfeccionado» (Francisco Manuel de Melo, Obras Métricas, edição cordenada por Maria Lucília Gonçalves Pires e José Adriano de Freitas Carvalho. Braga: Ediçōes APPACDM de Braga, 2006, 8). O estado «imperfeito» duma obra sua não constituía impedimento para que Francisco Manuel de Melo a fizesse imprimir, como ilustra o caso da «Tragedia. La escena en los Montes de la Luna", que levava no final a indicação "No se acabó» na edição isolada de Las Tres Musas del Melodino (1649), uma situação que se manteve na publicação lionesa das Obras Métricas (1665).

${ }^{11}$ Poderia resultar produtivo, na perspectiva aqui aludida, submeter Francisco Manuel de Melo a uma "crítica da carreira», de acordo com propostas avançadas nos últimos anos por estudiosos de universidades norte-americanos que tiveram a sua expressão inicial no volume European Literary Careers: the author from Antiquity to the Renaissance (Toronto: University of Toronto Press, 2002). Uma tentativa pioneira de aplicação a um autor português dos seus instrumentos teóricos pode encontrar-se num ensaio de Hélio J. S. Alves sobre Jerónimo Corte-Real: «Corte-Real, a Evolução da sua Arte», in Península.Revista de Estudos Ibéricos, 2. Porto: 2005, pp. 171-199.

${ }^{12}$ Francisco Manuel de Melo, Obras Métricas, ed. cit., II, p. 1019. 
Bocalino comenta que este, "compondo um poema misto, cuidou que o fazia heróico» ${ }^{13}$. A observação permite desde logo inferir que as categorias "heróico» e "misto» estariam muito próximas, a tal ponto que o próprio poeta, na hora de compor uma obra sua, poderia equivocar-se. Por outro lado, vemos atribuída a condição de «misto» a um poema que anda incluído entre as produçôes épicas na generalidade das histórias literárias. Infelizmente para nós, D. Francisco Manuel de Melo não explicita as razóes da reclassificação que propóe para a obra de Ercilla, deixando-nos na dúvida quanto ao que o levava a considerar a Araucana um poema «misto». No entanto, a segunda alusão a esta categoria que aparece no Hospital das Letras permite fazer alguma luz sobre este aspecto. Tratando de D. Francisco Rolim de Moura, o Autor faz as apresentaçóes: «Estes são os seus novíssimos do homem, Poema misto, e ainda místico, com muitas partes de moral e heróico» ${ }^{14}$. O esclarecimento que a personagem do apólogo dá a respeito da obra parece apontar no sentido de que a classificação seria atribuída a poemas que combinavam uma estrutura externa e um estilo de características épicas com um conteúdo de ordem predominantemente moral ou religiosa. Sendo assim, haveria que considerar como igualmente «mistos», pelo menos, o Poema del Angélico Doctor Sancto Thomaz, publicado por Manuel Tomás em 1625, e a obra de Miguel da Silveira El Macabeo, um poema saído à luz em 1638. Quanto ao primeiro, no seu Hospital das Letras D. Francisco Manuel de Melo apenas se lhe refere como um livro «em verso", enquanto Miguel da Silveira não lhe merece mais do que uma severa crítica quanto à desproporção entre o estilo elevado que emprega e a humildade dos assuntos a que o aplica. A condição genológica do poema é omitida.

Desta breve indagação na obra crítica de D. Francisco Manuel de Melo poderemos retirar que a categoria de "Poema misto» que o autor atribui à sua "Thetis Sacra», embora podendo definir algumas características de conteúdo específicas, situa-a, sem margem para dúvidas, no quadro das obras poéticas que a história literária tem considerado dentro do género épico.

Regressando ao texto explicativo que as Obras Métricas oferecem, talvez seja possível encontrar justificação para a designação de "poema misto" no assunto proposto. Segundo a descodificaçáo proposta na "alegoria do poema», este teria como objecto a exaltação de um acontecimento do domínio religioso: a celebração da primeira missa sobre as águas oceânicas. Um tema que pertence ao domínio do sagrado, portanto. Contudo, o canto deveria ter "todos os adornos da poesia cristã», o que nos parece indicar o propósito do autor de se servir da forma poética mais elevada, isto é, a estrutura e o estilo épicos. Em abono desta interpretação, podemos delimitar nas 102 oitavas que integram a "Thetis Sacra» as partes obrigatórias de qualquer poema épico. Para além do verso decassílabo clássico e da adopção da oitava rima como forma estrófica, é possível definir, com razoável segurança, os elementos que integram a estrutura externa característica do poema épico: proposição, invocação, dedicatória e narração encontram-se no poema, ainda que a sua posição no interior da obra nem sempre corresponda àquilo que poderíamos esperar. É o que se verifica, especialmente, com a Proposição. Por um lado, poderemos considerar que

\footnotetext{
${ }^{13}$ Jean Colomès, Le dialogue "Hospital das Letras" de D. Francisco Manuel de Melo, ed. cit., p. 43.

${ }^{14}$ Jean Colomès, Le dialogue "Hospital das Letras" de D. Francisco Manuel de Melo, ed. cit., p. 79
} 
as duas primeiras estrofes contêm a apresentação da matéria a desenvolver no canto, uma vez que nelas se alude à intenção de substituir o canto profano, inspirado por Apolo, por um novo canto, divinamente inspirado, em que o orbe celebre o Criador. No entanto, o texto não é explícito quanto à «fábula», passando imediatamente, a partir da terceira estrofe, à invocaçáo e, depois, à dedicatória. Contudo, as estrofes 7 e 8 retomam a proposição, referindo, agora com clareza, que a conquista dos mares para Cristo, simbolicamente representada pela realizaçáo da primeira eucaristia que os portugueses celebraram a bordo duma embarcação constitui o objecto do canto:

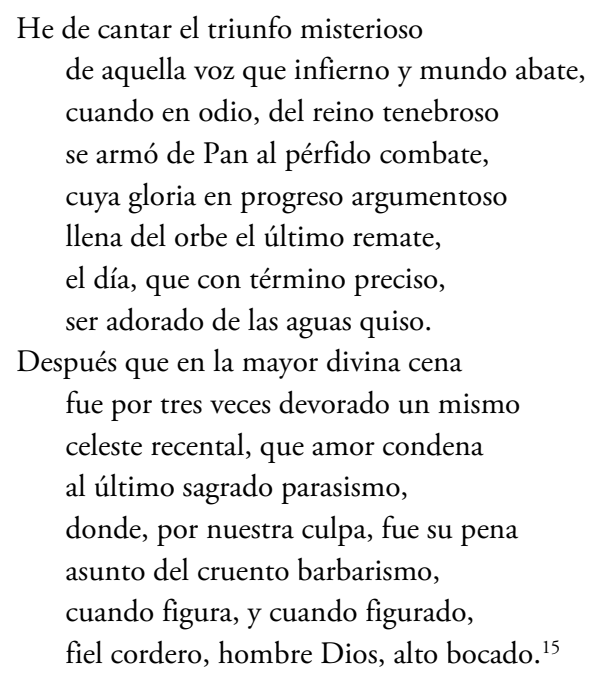

Entre estas duas proposiçóes - ou estas duas partes da proposição... - podemos encontrar, como referimos já, a invocação e a dedicatória. Cada uma ocupa duas estrofes. $\mathrm{Na}$ terceira e quarta oitavas, o poeta solicita a inspiração da Virgem Maria, em versos que sáo bem elucidativos quanto aos processos de que o autor se serve para, evocando a tradição literária do género épico, pô-la ao serviço da doutrina cristã:

Musa de Olimpo, no del Helicona

de nueve hermana, mas de nueve reina,

cuya planta es guirnalda que corona

al serafín, que más fulgores peina,

en quien el sol sus rayos perfecciona, por quien, monarca de las luces, reina, la menor que a tu cerco no haga ofensa, centella, para pluma, me dispensa.

\footnotetext{
${ }^{15}$ Francisco Manuel de Melo, Obras Métricas, ed. cit., II, p. 1002.
} 
Tú, que estrella del mar, el mar, la tierra

te llaman, decorando tu alto oficio;

pues jamás, como Jano, o abre, o cierra

Neptuno su cancel, crudo o propicio,

sin que acierte la voz, cuando más yerra,

buscando en ti benigno el beneficio,

hoy te busco, y a la tetis, que hoy consagro,

con milagros inspira en su milagro. ${ }^{16}$

Em linha com o assunto proposto para objecto do poema, nestas estrofes ressalta o propósito de D. Francisco Manuel de Melo de "cristianizar" o estilo épico, fazendo reverter os elementos mitológicos ornamentais destinados a elevar a linguagem e a adequála à dignidade das matérias versadas nas epopeias pagãs em motivos de exaltação e de glorificação das realidades cristãs. A referência à Virgem Maria como «musa de Olimpo, no del Helicona» é um exemplo flagrante deste procedimento.

Como acontece com a proposição, também a invocação se repete noutros momentos do poema. Nas estrofes 33-35, de novo o poeta se dirige à Virgem Maria, sob a designação de "Musa sacrosanta», solicitando-lhe que o «anime» e o "conduza» na realização da «empresa» em que se lançou. A inspiração mariana é ainda invocada uma última vez, nas estrofes 79-80, para que a Virgem conceda ao poeta «preciosa voz y un alto alento, / por quien recite la divina hazańa / del Verbo que en patíbulo incruento / su carne en pan convierte y la acompaña ${ }^{17}$. É verdade que a invocação reiterada às Musas em momentoschave dum poema épico não constitui uma singularidade da obra de D. Francisco. No entanto, vista a curta extensão do texto, não deixa de ser surpreendente. Servirá, pelo menos, para ilustrar a devoção mariana do autor...

A dedicatória, a D. Fr. Pedro de Sousa, confessor de D. Afonso VI e tio do Conde de Castelo Melhor, ocupa as estâncias 5 e 6 e contém uma referência circunstancial que pode ajudar a datar a composição deste poema. Os versos da sexta estrofe, nos quais se refere «bien que os tarde la mitra que os prepara / pues la que tarda más es la tiara ${ }^{18}$ parecem conter uma alusão à nomeação de Fr. Pedro de Sousa para o bispado de Angra do Heroísmo e ao arrastamento do processo de confirmação na cúria romana. Sabendo-se que o tio do Conde de Castelo Melhor haveria de falecer em 14 de Janeiro de 1668 sem que tivesse chegado a Bula de confirmação ${ }^{19}$, poderemos sugerir, sem arriscar muito, que esta "Thetis Sacra» deverá ter sido um dos últimos trabalhos poéticos de D. Francisco Manuel de Melo, se não mesmo o último, uma vez que deixou o mundo dos vivos em 24 de Agosto de 1666.

É possível que o desejo de prestar uma homenagem ao tio do seu protector político tenha levado o Melodino a publicar na edição lionesa das Obras Métricas uma versão ainda

\footnotetext{
${ }^{16}$ Francisco Manuel de Melo, Obras Métricas, ed. cit., II, pp. 1001-1002.

${ }^{17}$ Francisco Manuel de Melo, Obras Métricas, ed. cit., II, p. 1014.

${ }^{18}$ Francisco Manuel de Melo, Obras Métricas, ed. cit., II, p. 1002.

${ }^{19}$ Cf. António de Sousa de Macedo, D. Afonso VI (edição de Eduardo Brazão). Porto: Civilização, 1940, pp. 93-94 e Diogo Barbosa Machado, Biblioteca Lusitana, Coimbra, Atlântida Editora, 1967, III, p. 620.
} 
embrionária deste seu "poema misto». Como se compreende, é na narração que se torna mais visível a imperfeição da obra. A julgar pela sinopse e pelo que o autor pôde escrever, o poema deveria organizar-se em torno de dois núcleos narrativos: um, centrado na acção dos «monarcas cristianos que dilataron la fe» e dos «reyes y príncipes de Portugal que más se emplearaon en las conquistas de los infieles, haciendo venerar por nuevas regiones el nombre de Cristo, guardar su santa ley y conocer su santísima cruz»; o outro assunto polarizador da acçáo seria «la piedosísima acción que obraron los portugueses en el descubrimiento del Oriente, haciendo, por manos de sus sacerdotes, celebrar la primera misa que jamás en el mundo se había celebrado sobre el mar» ${ }^{20}$. No texto publicado, não é difícil detectar a presença destes dois segmentos, ainda que apenas em relação ao segundo exista um esboço de acção.

O processo de expansão da fé cristã pelo mundo é sumariamente enunciado nas estâncias que preenchem o espaço entre as duas primeiras invocaçóes - 8 a 32 - e inicia-se com a evocação da instituição da eucaristia, na última ceia, avançando, depois, para a pregação dos apóstolos, a acção de Constantino, a conversão da Ibéria e da Gália, culminando na vocação missionária da Lusitânia. Aqui chegados, o poeta interpela directamente, um a um, as personalidades da história nacional que, na sua perspectiva, mais contribuíram para dilatar a fé cristã no mundo, cumprindo, assim, o destino providencialista de Portugal. À razão de uma estância para cada um, são chamados ao poema o rei D. João I, o Infante D. Henrique, o Infante Santo D. Fernando, D. Afonso V, D. Manuel e D. Sebastião ${ }^{21}$. D. João III aparece em último lugar e está-lhe reservado um tratamento um pouco mais desenvolvido, porque o poeta lhe atribui a responsabilidade por ter tornado o oceano um mar cristão:

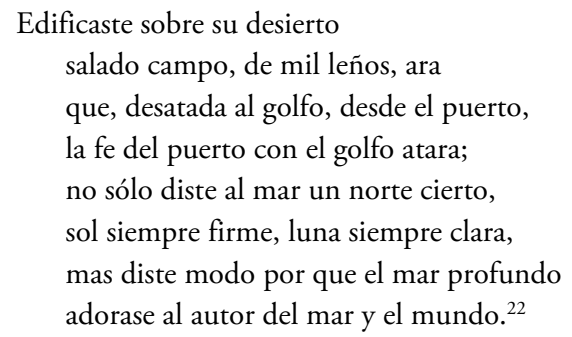

A evocação destas figuras não se integra em nenhum fio narrativo, por ténue que fosse. Surge no poema como uma galeria que o poeta percorre rapidamente, como se náo fosse mais do que um sumário onde quis fixar os pontos a desenvolver num momento mais adiantado do trabalho criativo.

A parte do texto ocupada pela evocação da primeira eucaristia marítima parece ter sido objecto de maior desenvolvimento. Tratado nas estâncias 36 a $102^{23}$, o assunto é desenvol-

\footnotetext{
${ }^{20}$ Francisco Manuel de Melo, Obras Métricas, ed. cit., II, p. 1019.

${ }^{21}$ Francisco Manuel de Melo, Obras Métricas, ed. cit., II, pp. 1004-1005.

${ }^{22}$ Francisco Manuel de Melo, Obras Métricas, ed. cit., II, p. 1006.

${ }^{23}$ Francisco Manuel de Melo, Obras Métricas, ed. cit., II, pp. 1007-1018.
} 
vido já através dum esboço de acção. Talvez numa sugestão camoniana, começa-se pela descrição da partida das naus e, enquanto estas se afastam da barra do Tejo, Deus encarrega a Fama de convocar todos os seres para o sacrifício eucarístico que será celebrado em pleno oceano:

Mas outra providencia, que su espanto, que a todo espanto y providencia humilla, introduciendo su decreto santo, por honra de su inmensa maravilla, manda a la Fama que, no en voz, sí en canto, al orbe suene, de una a la otra orilla, de donde llame, incite, atraiga, asombre, al serafín, al ave, al pez, al hombre. ${ }^{24}$

A sugestão da convocatória dum concílio universal constitui um evidente aceno à tradição das epopeias clássicas, mas serve, sobretudo, para sublinhar o significado transcendente da assembleia eucarística pela primeira vez celebrada sobre as águas, as quais são, assim, conquistadas para a fé cristã. Respondendo à chamada, todos os seres se dirigem para o local do sacrifício eucarístico, realizado numa nau transfigurada em templo. A descrição da celebração preenche a última vintena de estâncias, precedida da derradeira invocação à Virgem Mãe de Deus e encerra com a sugestão dum cortejo triunfal, em que a mesma nau que antes se metamorfoseara em templo sagrado se transforma, agora no carro alegórico da Fé triunfante.

Não sabemos se o texto da "Thetis Sacra" que podemos ler no fecho das Obras Métricas corresponde ao projecto inicial de D. Francisco Manuel de Melo. Acreditamos, contudo, que o poeta terá pensado este seu "poema misto» como um exercício literário de maior fôlego ${ }^{25}$, destinado a provar as suas capacidades nos terrenos exigentes da poesia épica. Não nos custa imaginar que este conjunto de 102 estâncias deveria ser alargado, dando lugar a uma divisão em cantos onde uma acção unificadora pudesse ser desenvolvida, de modo a conferir maior coesão narrativa à obra. As circunstâncias teráo levado o autor a publicar em 1665 um simples embrião da sua obra, um esboço a desenvolver. Um poema imperfeito que, no entanto, poderia contribuir para enriquecer a variedade das Obras Métricas, um valor estético especialmente apreciado pelo nosso autor.

\footnotetext{
${ }^{24}$ Francisco Manuel de Melo, Obras Métricas, ed. cit., II, p. 1008.

${ }^{25}$ Tendo em conta a dedicatória a D. Frei Pedro de Sousa, O.S.B., poderá especular-se que o texto, uma vez "perfeito", se destinaria a assinalar a esperada assunçáo do cargo de Bispo de Angra do Heroísmo pelo tio do Conde de Castelo Melhor, facto que, como já deixámos assinalado, não viria a ocorrer nem em vida de D. Francisco Manuel de Melo, nem do próprio D. Frei Pedro de Sousa.
} 
Série

Documentos

Imprensa da Universidade de Coimbra

Coimbra University Press

2010

- U

C • 